\title{
RESEARCH OF THE CAMERA CALIBRATION USING SERIES OF IMAGES WITH COMMON CENTER OF PROJECTION
}

\author{
Chibunichev A.G. ${ }^{1}$, Govorov A.V. ${ }^{1}$, Chernyshev V.E. ${ }^{1}$ \\ ${ }^{1}$ Moscow State University of geodesy and cartography (MIIGAiK), Moscow, Russia - agchib@ mail.ru
}

Technical Commission II

KEY WORDS: camera calibration, long focal length lenses, panoramic head, front nodal point, common center of projection, testobject

\begin{abstract}
:
The method for calibration of cameras equipped with long focal distance lens is researched in the present work. The basic idea is as follows. The camera to be calibrated is placed on the tripod with panoramic head. The main condition of panorama shooting is that the rotation center of the camera and the front nodal point of the lens should be the same. The camera is calibrated based on a series of images of a test object with a common center of projection. Special software has been created for this purpose. The results of experimental studies on digital simulated data and for a real camera Hasselblad H4D-60 are presented. Results of these experiments show that use of common projection center allow to increase accuracy of the calibration process of the long focal length cameras.
\end{abstract}

\section{INTRODUCTION}

The problem of calibration of cameras in this case is consists of the following. If we try to calibrate long focus camera using ordinary test-object (Figure 1) then we will note the significant degradation of precision of results or even the failure of calibration procedure may occur. It is due to bad geometrical conditions. A small number of points to be measured are in each photograph, very sharp intersection angle and insufficient depth (difference in position between far and near points) of the test-object (Figure 2). It is obvious that for long focal distance calibration the special test-object should be constructed.

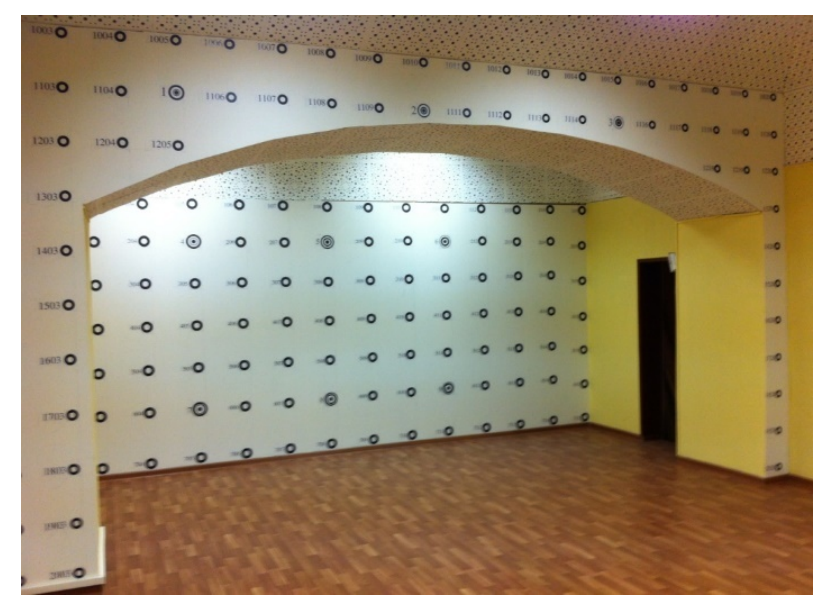

Figure 1. Test-object of (MIIGAiK) for camera calibration.

The problem of calibration of long focal length camera is discussed in the photogrammetric literature (Cramer, 2004), (Cramer et al, 2017), (Ergun, 2010), (Knyaz, 2015), (Fryer, 1996), (Remondino and Fraser, 2006), (Shortis, 2012). (Stamatopoulos, 2010), (Stamatopoulos, 2011) consider that two prospective ap-

\footnotetext{
${ }^{*}$ Corresponding author
}

proaches are available. The first is to investigate means to better accommodate numerical ill-conditioning, and the second is to look to the formulation of the functional model.

(Liang et al, 2014) propose a robust algorithm to calibrate the camera with a long focal length without using additional devices by adding a regularization term to computational process.(Robson et al, 2016) represents results of long focal length camera calibration in Violet and IR light.

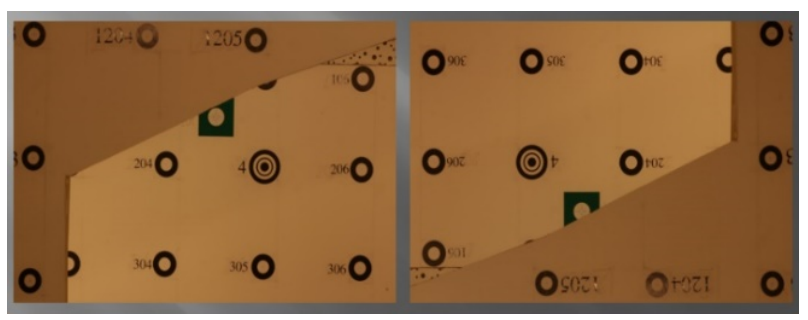

Figure 2. Photos of the test object with a long-focus camera.

\section{CAMERA CALIBRATION USING COMMON CENTER OF PROJECTION}

We suggest another approach to the calibration process. The camera to be calibrated is placed on the tripod with panoramic head (Figure 3) used by photographers to get high-quality panoramas. The main condition of panorama shooting is that the rotation center of the camera and the front nodal point of the lens should be the same.

In this case all photographs will have common center of projection. The number of photographs depends on cameras field of view and on geometrical dimensions of used test-object. The position of the front nodal point for common user lenses is published in photography literature. The position of the front nodal 


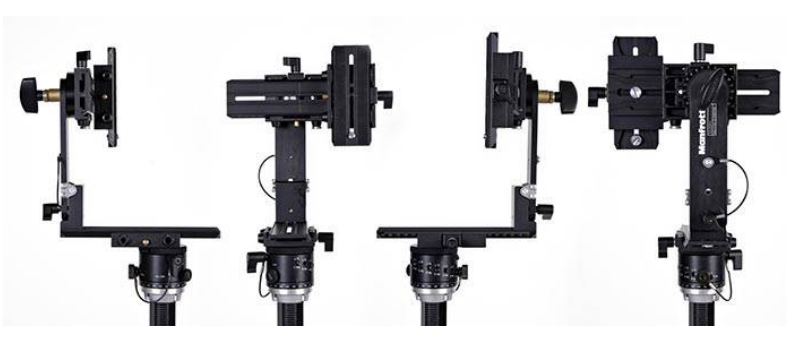

Figure 3. Panoramic head.

point can be found using vertical lines test-object. The principle of the determination is shown on Figure 4.

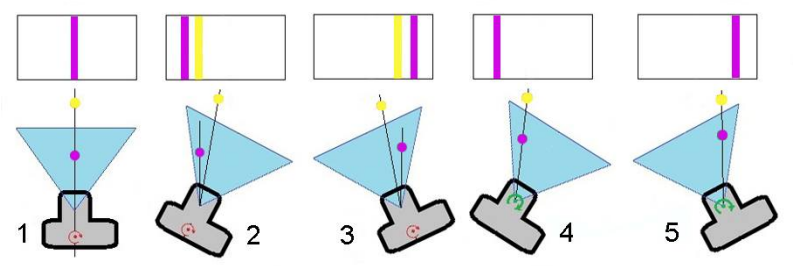

Figure 4. Finding the front nodal point.

In the field of view of the camera two vertical line objects are located. We used wires weighted near the floor for this purpose. Rotating and shifting camera in panoramic head one should find the position of the camera when two vertical objects will be seen in one sight line.

The next step is making series of photographs of the test-object while rotation of the camera around center of projection to the left and to the right in order to get more points of the test-object (Figure 5).

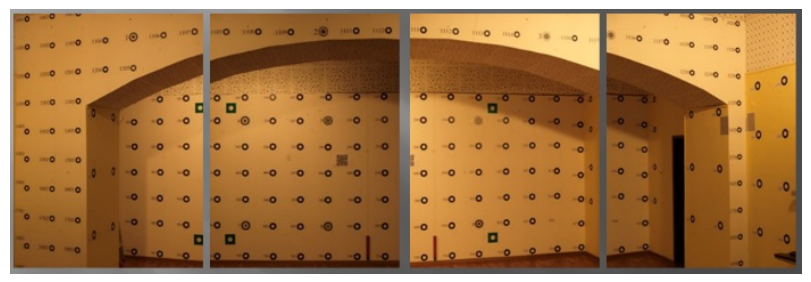

Figure 5. Example of shooting a test-object with a long-focus camera.

The image coordinates of the object points should be measured manually or automatically. Further processing is performed in original software ProjNet designed at the chair of photogrammetry MIIGAiK.

The ProjNet has an option (in red circle at Figure 6) to perform a bundle adjustment with self-calibration and to do calibration using photographs taken from the single projection center with definition of its coordinates in the test-object coordinate system.

\section{EXPERIMENTAL STUDIES}

\subsection{Experiment on the simulated data}

At the beginning suggested calibration method was checked up using digital simulated data. The following steps were implemented.

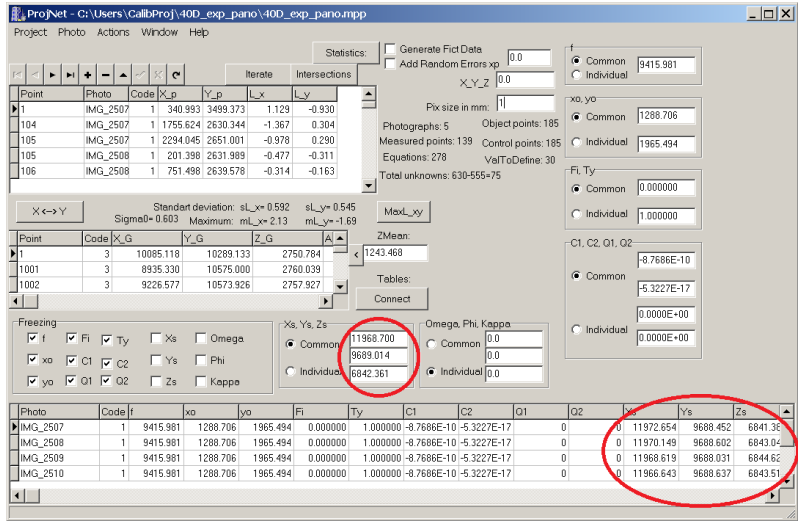

Figure 6. Software interface to calibrate the cameras with a common center of projection.

- Setting desirable intrinsic parameters of the camera.

- Choosing a virtual test-object.

- Choosing the number of cameras and their position and orientation.

- Computing image coordinates.

- Computing calibration parameters.

To test calibration process the following experimental work was performed. Camera parameters (true values) were the following. Focal distance $f=1000 \mathrm{~mm}$, frame dimensions $200 \times 200 \mathrm{~mm}$, coordinates of the principal point $\mathrm{xo}=\mathrm{yo}=0$. The distribution of points in the image plate is shown in Figure 7. 9 photographs were created as it is shown at Figure 8.

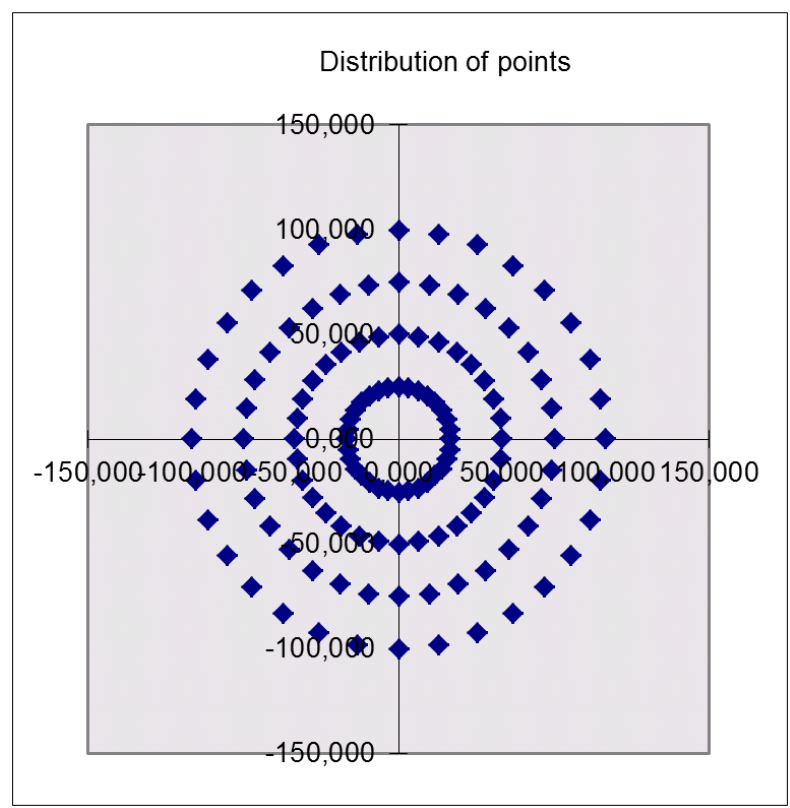

Figure 7. Scheme of the points location in the simulated image.

Total number of points on each photograph is 128 and they are grouped in 4 levels ( 32 points in each), as shown in Figure 9. 


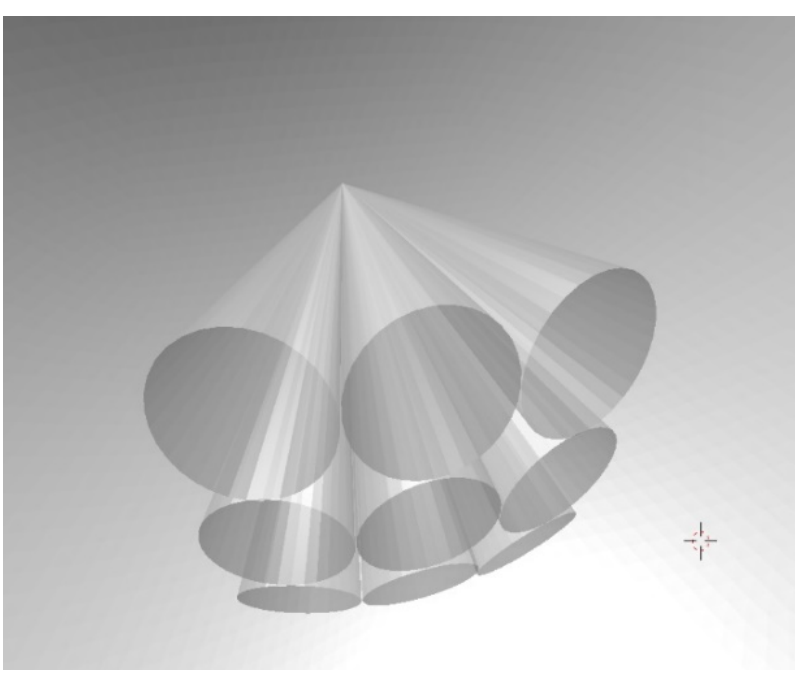

Figure 8. Scheme of the simulated images location.

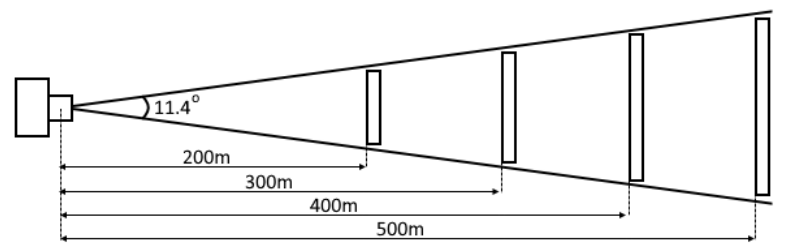

Figure 9. Scheme of formation of the simulated images.

Random errors were added to image coordinates with std.error of $0.01 \mathrm{~mm}$ and to test-object points with std.error of $1 \mathrm{~mm} .10$ realizations were done. The results (RMS of deviations from true values in $\mathrm{mm}$ ) are shown in the Table 1.

\begin{tabular}{|c|c|c|}
\hline $\begin{array}{c}\text { RMS } \\
(\mathrm{mm})\end{array}$ & $\begin{array}{c}\text { Individual } \\
\text { projection centers }\end{array}$ & $\begin{array}{c}\text { Common } \\
\text { center of projection }\end{array}$ \\
\hline $\mathrm{f}$ & 0.047 & 0.017 \\
\hline xo & 0.372 & 0.352 \\
\hline yo & 0.280 & 0.284 \\
\hline
\end{tabular}

Table 1. Evaluation of accuracy by simulated data.

\subsection{Experiment on the real data}

Camera - Hasselblad H4D-60, lens - Hasselblad H 100 mm, f/2.2. Photographs used for calibration are shown at Figure 5. Calibration results are presented in the Table 2.

\begin{tabular}{|c|c|c|}
\hline & $\begin{array}{c}\text { Individual } \\
\text { projection centers }\end{array}$ & $\begin{array}{c}\text { Common } \\
\text { center of projection }\end{array}$ \\
\hline f, pix & $16663.77 \pm 2.33$ & $16656.36 \pm 1.44$ \\
xo, pix & $3363.18 \pm 2.32$ & $3360.73 \pm 2.39$ \\
yo, pix & $4522.66 \pm 2.50$ & $4532.29 \pm 1.92$ \\
$K_{1}$ & $-1.86 e^{-10} \pm 9.87 e^{-12}$ & $-2.02 e^{-10} \pm 9.94 e^{-12}$ \\
$K_{2}$ & $-1.17 e^{-18} \pm 3.24 e^{-19}$ & $-7.81 e^{-19} \pm 3.35 e^{-19}$ \\
\hline
\end{tabular}

Table 2. The results of camera calibration - Hasselblad H4D-60.
Results of photogrammetric processing of the stereopair (49 points of the test-object) using two variants of calibration parameters are shown in the Table 3.

\begin{tabular}{|c|c|c|}
\hline $\begin{array}{c}\text { RMS } \\
(\mathrm{mm})\end{array}$ & $\begin{array}{c}\text { Individual } \\
\text { projection centers }\end{array}$ & $\begin{array}{c}\text { Common } \\
\text { center of projection }\end{array}$ \\
\hline $\mathrm{X}, \mathrm{mm}$ & 0.17 & 0.16 \\
\hline $\mathrm{Y}, \mathrm{mm}$ & 0.21 & 0.11 \\
\hline $\mathrm{Z}, \mathrm{mm}$ & 0.50 & 0.31 \\
\hline
\end{tabular}

Table 3. Results of photogrammetric processing of the stereopair.

\section{CONCLUSION}

Results of our experiments show that use of common projection center allow to increase accuracy of the calibration process of the long focal length cameras.

\section{ACKNOWLEDGEMENTS}

The work was performed with the support by Grant 17-29-04410 of Russian Foundation for Basic Research (RFBR).

\section{REFERENCES}

Brown D.C. 1971. Close Range Camera Calibration. Photogrammetric Engineering 37 (8), pp. 855- 866.

Cramer M, Przybilla H.-J., Zurhorst A. 2017. UAV Cameras: Overview and Geometric Calibration Benchmark. DOI:10.5194/isprs-archives-xlii-2-w6-85-2017

Cramer, M., 2004. EuroSDR network on digital camera calibration. International Archives of Photogrammetry, Remote Sensing and Spatial Information Sciences, XXXV-B6, pp. 204-209.

Ergun B. 2010. Photogrammetric observing the variation of intrinsic parameters for zoom lenses. Scientific Research and Essays Vol. 5(5), pp. 461-467, 4 March, 2010.

Fryer, J. G. 1996. Camera calibration. In Close Range Photogrammetry and Machine Vision. K. B. Atkinson (ed.). Caithness, United Kingdom: Whittles Publishing, pp 156-179.

Knyaz, V.A. 2015. SCALABLE PHOTOGRAMMETRIC MOTION CAPTURE SYSTEM MOSCA: DEVELOPMENT AND APPLICATION, Int. Arch. Photogramm. Remote Sens. Spatial Inf. Sci., XL-5/W6, 43-49, https://doi.org/10.5194/isprsarchivesXL-5-W6-43-2015, 2015.

Mingpei Liang, Xinyu Huang, Chung-Hao Chen, Gaolin Zheng, and Alade Tokuta. 2014. Robust Calibration of Cameras with Telephoto Lens Using Regularized Least Squares. Mathematical Problems in Engineering. Hindawi Publishing Corporation. Volume 2014, Article ID 689429, 9 pages.

Remondino, F. and Fraser, C. S., 2006. Digital camera calibration methods: considerations and comparisons. International Archives of Photogrammetry, Remote Sensing and Spatial Information Sciences, Vol. XXXVI, Part 5, pp. 266-272. 
Robson S., Beyer H.A, Shortis M.R. 1996. Principal Point Behaviour and Calibration Parameter Models for Kodak DCS Cameras. The Photogrammetric Record. 16(92): 165-186.

Robson S., MacDonald L., Kyle S., Shortis M.R. 2016. Close Range Calibration of Long Focal Length Lenses in a Changing Environment. International Archives of the Photogrammetry, Remote Sensing and Spatial Information Sciences. Vol. XLI-B5.

Shortis M.R. 2012. Multi-lens, Multi-camera Calibration of Sony Alpha NEX 5 Digital Cameras. Melbourn: Geospatial Sciences, RMIT 2012.

Stamatopoulos C. 2011. Orientation and Calibration of Long Focal Length Cameras in Digital Close-Range Photogrammetry. $\mathrm{PhD}$ Thesis.

Stamatopoulos C., Fraser C.S. 2011. Calibration of Long Focal Length Cameras in Close Range Photogrammetry. The Photogrammetric Record. 26(135):339-360.

Stamatopoulos C., Fraser C.S., Cronk S. 2010. On the SelfCalibration of Long Focal Length Lenses. International Archives of the Photogrammetry, Remote Sensing and Spatial Information Sciences. Vol. XXXVIII Part 5. 